\section{Improved Drought Tolerance in Marigold by Manipulation of Root Growth with Buffered-phosphorus Nutrition}

\author{
Kristian Borch ${ }^{1}$, Carter Miller, Kathleen M. Brown, and \\ Jonathan P. Lynch \\ Department of Horticulture, Pennsylvania State University, University Park, \\ PA 16802
}

Additional index words. postproduction, Tagetes patula, water stress

\begin{abstract}
A series of experiments was conducted to investigate the response to drought stress of marigold (Tagetes patula L. 'Janie Tangerine') plants grown with reduced phosphorus. Plants were grown with conventional phosphorus fertilization $(1 \mathrm{~mm}$, control) or one of two levels of alumina-buffered phosphorus (Al-P), 21 or $5 \mu \mathrm{M}$. Plants supplied with $21 \mu \mathrm{M}$ Al-P produced plants with equal total dry weight, more flowers and reduced leaf area compared to control plants. Whole-plant photosynthetic $\mathrm{CO}_{2}$ assimilation expressed on a leaf area basis was nearly twice as high in $21 \mu \mathrm{M} \mathrm{Al-P}$ plants as in controls, probably as a result of reduced intraplant shading. In plants supplied with 21 $\mu \mathrm{M} \mathrm{Al-P,}$ smaller leaf area resulted in reduced whole-plant transpiration. Moreover, the relative water content of the growing medium was significantly lower at wilting with 21 $\mu \mathrm{M}$ Al-P than for control or $5 \mu \mathrm{M}$ Al-P regimes. The improved water acquisition with 21 $\mu \mathrm{M}$ Al-P could be explained by increased root proliferation via longer main roots and less densely distributed lateral roots. The results indicate that optimizing phosphorus nutrition with solid-phase buffered-phosphorus fertilizer improves drought tolerance by reducing transpiration and increasing water acquisition from the medium.
\end{abstract}

Plants in soilless media are traditionally grown with excessive phosphorus levels, which may have detrimental effects on plant growth and performance (Hansen and Lynch, 1998). Studies using buffered-phosphorus solutions show that plants can grow well at phosphorus levels as low as $10 \mu \mathrm{M}$ (Borch et al., 1998; Lin et al., 1996; Lynch et al., 1991), which is in the range of phosphorus concentrations found in fertile soils (Reisenauer, 1964). Such plants usually have a higher root-to-shoot ratio than plants grown at higher phosphorus levels (Anuradha and Narayanan, 1991; Borch et al., 1999; Lynch and Beebe, 1995).

Increased root : shoot ratio, which also results from application of growth retardants, is well known to improve postharvest stress tolerance in bedding plants (Armitage, 1993). In a previous experiment, we found that impatiens (Impatiens walleriana Hook.) and marigold (Tagetes patula L.) plants grown with alumina-buffered phosphorus (Al-P, 6

Received for publication 22 Oct. 2001. Accepted for publication 1 June 2002. This research was supported by The Danish Academy of Science, the Pennsylvania Dept. of Agriculture, The American Floral Endowment, The Fred C. Gloeckner Foundation, and Bedding Plants Foundation. We thank Kai Nielsen, Michelle Williams, Conny Hansen, Bob Ebel, and Melissa Ho for valuable comments and suggestions.

${ }^{1}$ Current address: Systems Analysis Dept., Risoe National Laboratory, P.O. Box 49, 4000 Roskilde, Denmark. and $35 \mu \mathrm{M} \mathrm{P}$ ) were less affected by a brief period of drought than plants conventionally fertilized with soluble phosphorus at $1 \mathrm{~mm}$ (Borch et al., 1998). Marigold plants had more uniform distribution of roots throughout the medium, which may have partially accounted for slower wilting. However, impatiens plants had no obvious changes in root distribution, but still showed slower wilting. Both species had reduced leaf area, which would reduce water loss (Borch et al., 1998).

The objective of this experiment was to investigate growth and drought responses of plants grown at various phosphorus levels to determine the mechanisms by which lower, but buffered, phosphorus increases drought tolerance. We examined root morphology, whole-plant transpiration, stomatal conductance, relative water content, and $\mathrm{CO}_{2}$ assimilation.

\section{Materials and Methods}

Marigolds ('Janie Tangerine') were germinated in low-phosphorus peat medium and grown in a greenhouse at University Park, Pa. (lat. $41^{\circ} \mathrm{N}$ ) without supplemental light. Day and night temperatures were $24.4 \pm 2.4{ }^{\circ} \mathrm{C}$ and $20.9 \pm 0.5^{\circ} \mathrm{C}$, respectively. Seeds were germinated in December and transplanted to 0.58-L containers after 2 weeks. Except for plants used in the root structure and water utilization experiment, plants were grown in sphagnum peat (Premier Horticulture, Red Hill, Pa.) and fertilized by irrigation with a $15 \mathrm{~N}-0 \mathrm{P}-12.4 \mathrm{~K}$ fertilizer (Peters Professional
Dark Weather Feed 15-0-15; Scotts-Sierra Horticultural Products Co. Marysville, Ohio) mixed to $200 \mathrm{mg} \cdot \mathrm{L}^{-1}(14.3 \mathrm{~mm}) \mathrm{N}$ according to package directions. Fertilization and irrigation were applied via a drip system for the transpiration experiment, and via subirrigation for the other experiments. The basic nutrient solution, which was changed once a week, contained the following nutrients (in $\mu \mathrm{M}): 12,400 \mathrm{NO}_{3}-\mathrm{N}, 1900$ urea-N, $4300 \mathrm{~K}$, $3700 \mathrm{Ca}, 0.008 \mathrm{~B}, 8.3 \mathrm{Cu}, 12 \mathrm{Fe}, 6.1 \mathrm{Mn}, 0.13$ $\mathrm{Mo}, 0.52 \mathrm{Zn} . \mathrm{K}_{2} \mathrm{HPO}_{4}$ (providing $1 \mathrm{~mm} \mathrm{P}$ and $2 \mathrm{~mm} \mathrm{~K}$ ) was added to the nutrient solution of the control plants. The reduced phosphorus plants were grown in the same peat medium amended with $1 \%(\mathrm{w} / \mathrm{v})$ phosphorus-charged alumina ( $\mathrm{P}-\mathrm{Al}_{2} \mathrm{O}_{3}$, abbreviated Al-P) (Elliott et al., 1983) and irrigated with the same nutrient solution as supplied to the control except that there was no $\mathrm{K}_{2} \mathrm{HPO}_{4}$ added to the solution, leaving the phosphorus-charged alumina as the only P source. Alumina was charged with two levels of phosphorus by rinsing acidified alumina with $\mathrm{K}_{2} \mathrm{HPO}_{4}$ as described by Lin et al. (1996) giving two levels of phosphorus desorption: 5 and $21 \mu \mathrm{MAl}$ A.P. Plants analyzed for root structure were grown in a calcined clay (SERAMIS; Effem, Mogendorf, Germany) (Starkey and Pedersen, 1997). Other aspects of cultivation were identical to the peat experiments.

Leachate was sampled weekly until anthesis by collecting solution dripping from the pot after irrigation and analyzed using a phospho-molybdenum blue method (Murphy and Riley, 1962). Phosphorus concentration in the leachate of control plants was $1.07 \pm 0.16$ $\mathrm{mm}$; and for the two Al-P treatments was $21 \pm$ $5.6 \mu \mathrm{M}$ and $5 \pm 2.0 \mu \mathrm{M}$ (means $\pm \mathrm{SE})$.

Transpiration experiment. The aim of this experiment was to describe transpiration and evaporation from plants grown with three different phosphorus treatments. At anthesis, the plants were moved from the greenhouse to a growth chamber with $45 \mu \mathrm{mol} \cdot \mathrm{m}^{-2} \cdot \mathrm{s}^{-1}$ photosynthetic photon flux density $(P P F D)$ for $12 \mathrm{~h}$ per day and a constant temperature of $25 \pm 2.1{ }^{\circ} \mathrm{C}$ and relative humidity (RH) of $30 \% \pm 3.4 \%$. Plants were acclimatized to the growth chamber environment for $24 \mathrm{~h}$ and irrigated to their effective water holding capacity (Elliott, 1992) by submergence in 4 $\mathrm{cm}$ water and assuring that the surface was saturated. The surface of the medium was covered with plastic to prevent evaporation. Water loss was continuously monitored gravimetrically for $72 \mathrm{~h}$ using 12 thin beam load cells (LCD-816G; Omega Technology Co., Stamford, Conn.) mounted on an aluminum beam. From each load cell, a lightweight platform was suspended on which one potted plant was placed. The load cells were excited with 6 V DC low-noise electrical supply and connected via a general purpose terminal panel (T71-GP; Strawberry Tree, Sunnyvale, Calif.). The plants were weighed continuously and the data were logged to a DynaRes-16 data acquisition board (DR-16, Strawberry Tree). The software package QuickLog PC vers. 2.4 was used to monitor data acquisition and store data. A standard curve was obtained 
for individual load cells using mass standards yielding a $0.2-\mathrm{g}$ precision. To distinguish between transpiration and evaporation, plants were rehydrated and recordings were repeated with the medium surface uncovered to allow evaporation in addition to transpiration. The difference between these measurements was assumed to be evaporation. After the load cell recordings the plants were harvested to measure leaf area. Transpiration rates during dark and light periods were calculated using linear regression on the data collected 1-4 h after the onset of each light or dark period.

Root structure and water utilization. The aim of this experiment was to identify the relationships among root structure, phosphorus concentration and water utilization. To make this possible, the plants were grown in SERAMIS, which separates easily from the roots. At anthesis, these plants were transferred to a growth chamber with low light (45 $\mu \mathrm{mol} \cdot \mathrm{m}^{-2} \cdot \mathrm{s}^{-1}$ PPFD for $16 \mathrm{~h}$ per day), constant temperature of $21{ }^{\circ} \mathrm{C}$ and $35 \% \mathrm{RH}$ and acclimatized for $2 \mathrm{~d}$ before drought treatment was started. The plants were then irrigated to their effective water holding capacity, whole plants were weighed, and stomatal conductance of two fully expanded leaves in the upper half of the canopy was recorded with an Mk3 porometer (Delta-T, Cambridge, England). The plants were not irrigated while they were in the chamber. The stomatal conductance and weight of the plants were recorded once every day until wilting. Photosynthesis was recorded before and $2 \mathrm{~d}$ after the initiation of drought stress with a LI-COR 6200 portable photosynthesis system (LI-COR, Lincoln, Nebr.) operated as a closed system. Photosynthesis was measured in a 36Lcuvette enclosing the whole plant (including roots) for $60 \mathrm{~s}$. PPFD during photosynthesis measurements was $73 \pm 18 \mu \mathrm{mol} \cdot \mathrm{m}^{-2} \cdot \mathrm{s}^{-1}$. Final measurements were taken on each plant when midday stomatal conductance dropped below $27.5 \mathrm{~mol} \cdot \mathrm{m}^{-2} \cdot \mathrm{s}^{-1}$ (as compared to controls at $\left.85-110 \mathrm{~mol} \cdot \mathrm{m}^{-2} \cdot \mathrm{s}^{-1}\right)$ and visible wilting occurred. Plants were harvested to record leaf area and the roots were separated from the growth medium. A subsample of the roots was stained in a $2 \%$ neutral red solution for at least $2 \mathrm{~h}$ and digitally analyzed for root length and diameter using Delta-T-Scan (Delta-T). The subsample and the rest of the root system were oven dried separately at $70{ }^{\circ} \mathrm{C}$ for $48 \mathrm{~h}$ to determine dry weight. The growth medium was dried to calculate relative water content $\left(\mathrm{RWC}_{\mathrm{pot}}\right)\left(\mathrm{RWC}_{\mathrm{pot}}=[(\mathrm{wW}-\mathrm{wd}) /(\mathrm{wf}-\mathrm{wd})]\right.$ $\times 100$, where wf is the pot weight at effective water holding capacity, ww is pot weight at wilting, and wd is weight of the pot medium and pot after $48 \mathrm{~h}$ of oven drying; Hsiao, 1990). The effective water holding capacity was determined after subirrigating to a depth of $4 \mathrm{~cm}$, followed by free drainage. The effective water holding capacity of SERAMIS was $2.2 \mathrm{~g}$ water per gram of medium.

Long-term drought and longevity. Peat grown plants were placed in a growth chamber as described in the previous experiment. Daily water use was determined gravimetrically by weighing each plant morning and evening for 2 d. This was repeated after rewatering. Drought stress was applied to 10 plants by daily subirrigation with half the volume of water used prior to the drought treatment. Ten plants of each phosphorus treatment were irrigated regularly and served as controls. After 3 weeks, drought stress was assessed by recording stomatal conductance. $\mathrm{RWC}_{\text {pot }}$ was measured as described above. The effective water holding capacity of the peat-based medium was $3.6 \mathrm{~g}$ water per $\mathrm{g}$ medium. The two youngest fully matured leaves were used to record relative water content of the leaf $\left(\mathrm{RWC}_{\text {leaf }}\right)$ using $\mathrm{RWC}_{\text {leaf }}=$ $[(w w-w d) /(w t-w d)] \times 100$, where wt is leaf turgid weight, ww refers to leaf weight at the wilting point and wd is leaf dry weight. The leaf was then submerged in distilled water at $22{ }^{\circ} \mathrm{C}$, placed under a light source for $24 \mathrm{~h}$, blotted dry and weighed to determine turgid weight. After drying for $48 \mathrm{~h}$ at $60^{\circ} \mathrm{C}$, the leaf was weighed again to determine wd. Flowers, wilted flowers, and buds were counted and the shoots were oven dried for $48 \mathrm{~h}$ to determine dry weight.
Statistical analysis. Data were analyzed using the PC-statistical package JMP (SAS Inst., Cary, N.C.). Data were analyzed with analysis of variance (ANOVA) (split plot design). Contrasts were used to test for significant differences among means. The notation "ns" means there is no significant difference at a $5 \%$ confidence level.

\section{Results}

Transpiration. Water loss through transpiration was significantly lower for plants grown with Al-P than for control plants over a 72-h period with no irrigation (Fig. 1). The rate of water loss through evaporation alone was about the same for control and $21 \mu \mathrm{M} \mathrm{Al}-\mathrm{P}$ treatments, but was about twice as high for plants grown with $5 \mu \mathrm{MAl}-\mathrm{P}$ (not shown). Mean whole-shoot transpiration rates, calculated as the slopes of the linear segments of the water loss curves, were higher for control plants in both the light and the dark (Fig. 2). There was also a significant difference between 21 and

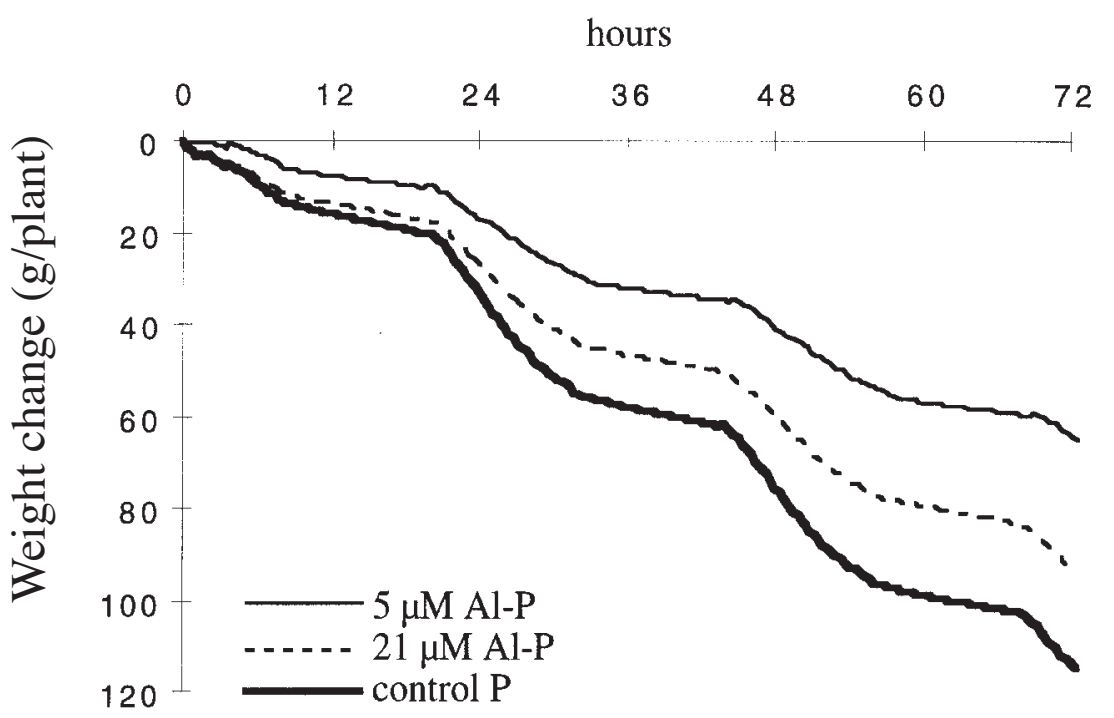

Fig. 1. Transpiration monitored for $72 \mathrm{~h}$ as gravimetric water loss from marigold plants at anthesis grown with three levels of $\mathrm{P}$ (control (1 mm soluble P), $21 \mu \mathrm{m} \mathrm{Al-P}$ and $5 \mu \mathrm{M} \mathrm{Al}-\mathrm{P}$ ). Values are means of eight plants.

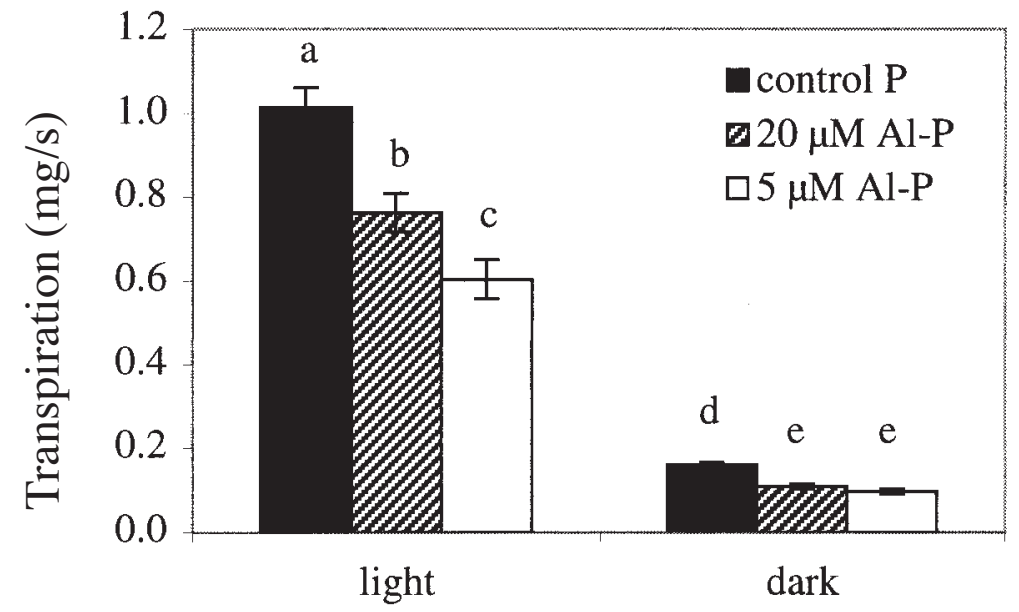

Fig. 2. Transpiration rates of whole plants grown in control P, $21 \mu \mathrm{M} \mathrm{Al-P}$ and $5 \mu \mathrm{M}$ Al-P. Rates were calculated from the slopes of the water loss curves (Fig. 1) over all $3 \mathrm{~d}$ using the data beginning $1 \mathrm{~h}$ after transfer to light or dark and continuing for $3 \mathrm{~h}$. Values are means of eight plants $+\mathrm{SE}$. 
$5 \mu \mathrm{M}$ Al-P fertilized plants in transpiration rate during the light periods (Fig. 2). When midday transpiration was expressed on a leaf area basis, phosphorus treatments (control, 2.24 $\pm 0.10 ; 21$ $\mu \mathrm{M}$ Al-P, $2.43 \pm 0.15 ; 5 \mu \mathrm{M}$ Al-P, $2.20 \pm 0.17$ among P treatments in transpiration during the dark period if transpiration rates were calculated on a leaf area basis (data not shown). Leaf area and total shoot dry weight decreased with decreasing phosphorus (Table 1).

Root structure and water utilization. In plants grown in SERAMIS, leaf area was again reduced with decreased phosphorus availability (Table 2). There were no significant differences between control and $21 \mu \mathrm{M}$ Al-P treatments for total dry weight (DW) of plants including the roots, but total DW was substantially lower for $5 \mu \mathrm{MAl}$-P plants (Table 2). There were no significant $P$ effects on root : shoot DW ratio (not shown). Root diameter was not reduced by $21 \mu \mathrm{MAl}$ A compared with controls, but was lower in $5 \mu \mathrm{M}$ Al-P roots. Total root length was about twice as great in 21 $\mu \mathrm{MAl}-\mathrm{Proots}$ as in the other treatments (Table 2 ). When irrigation was withheld, all control plants wilted (midday stomatal conductance below $27.5 \mathrm{~mol} \cdot \mathrm{m}^{-2} \cdot \mathrm{s}^{-1}$ ) after $3.5 \mathrm{~d}$, while 21 $\mu \mathrm{M}$ Al-P plants wilted after roughly $4.5 \mathrm{~d}$ and $5 \mu \mathrm{M}$ Al-P plants wilted after $5 \mathrm{~d}$ (data not shown). $\mathrm{RWC}_{\text {pot }}$ at wilting was significantly lower in $21 \mu \mathrm{M} \mathrm{Al}$-P plants compared to control and $5 \mu \mathrm{M}$ Al-P plants (Table 2). Stomatal among phosphorus treatments $(\mathrm{F}=1.78$, data not shown), indicating similar degree of water stress. Density of first- and secondorder lateral roots was about one-third less in Al-P fertilized than in control roots (Fig. 3). A significant correlation was found between total root length and $\mathrm{RWC}_{\text {pot }}$ (Fig. 4).

Net photosynthesis $\left(\mathrm{CO}_{2}^{\text {pot }}\right.$ assimilation rate $)$ per unit leaf area was about twice as high in $21 \mu \mathrm{M}$ Al-P plants as in $5 \mu \mathrm{m} \mathrm{Al-P}$ or control plants (data not shown) and was not significantly different after recovery from drought within P treatments.

Longevity and long-term drought. After three weeks of reduced irrigation, leaves were

Table 1. Shoot dry weight (DW) and leaf area for plants grown with different $\mathrm{P}$ levels. Values are means of 10 plants \pm SE. Different letters indicate significant difference on a $5 \%$ level ( $t$ test).

\begin{tabular}{lcc}
\hline P & $\begin{array}{c}\text { Shoot DW } \\
\text { availability }\end{array}$ & $\begin{array}{c}\text { Leaf area } \\
\left(\mathrm{cm}^{2}\right)\end{array}$ \\
\hline Control & $1.07 \pm 0.08 \mathrm{a}$ & $45.2 \pm 0.4 \mathrm{a}$ \\
$21 \mu \mathrm{M}$ Al-P & $0.74 \pm 0.03 \mathrm{~b}$ & $31.3 \pm 0.2 \mathrm{~b}$ \\
$5 \mu \mathrm{M}$ Al-P & $0.63 \pm 0.03 \mathrm{c}$ & $27.4 \pm 0.3 \mathrm{~b}$ \\
\hline
\end{tabular}
there were no significant differences among the $\left.\mathrm{g} \cdot \mathrm{m}^{-2} \cdot \mathrm{s}^{-1}\right)$. Likewise, there were no differences conductance was not significantly different

not visibly wilted, but the lower leaves were yellowing or had abscised, indicating severe drought stress. Stomatal conductance values at that time were $31.4 \pm 16.5,51.1 \pm 16.5$, and $41.8 \pm 13.8 \mathrm{~mol} \cdot \mathrm{m}^{-2} \cdot \mathrm{s}^{-1}$ in control, $21 \mu \mathrm{M} \mathrm{Al}-\mathrm{P}$ and $5 \mu \mathrm{M}$ Al-P plants respectively. Relative water content of the medium $\left(\mathrm{RWC}_{\mathrm{pot}}\right)$ after drought was significantly higher in $5 \mu \mathrm{M}$ Al-P plants than the two other phosphorus treatments, while $\mathrm{RWC}_{\text {leaf }}$ after drought was not significantly affected by phosphorus treatments (Fig. 5).

Dry weight of the shoot was much lower in $5 \mu \mathrm{M}$ Al-P plants than in plants from other phosphorus treatments ( $2 \mathrm{~g}$ in $5 \mu \mathrm{M} \mathrm{Al}-\mathrm{P}$ plants vs. $\approx 8 \mathrm{~g}$ in control and $21 \mu \mathrm{M} \mathrm{Al-P}$ plants). Drought had no effect on shoot DW in control and $21 \mu \mathrm{MAl}$-P plants but reduced it by nearly $50 \%$ in $5 \mu \mathrm{M} \mathrm{Al-P}$ plants. The percentage of wilted flowers after long-term drought was not significantly different between control and 21 $\mu \mathrm{M} \mathrm{Al-P}$ plants (45\% and $42 \%$, respectively), but was greater $(74 \%)$ in $5 \mu \mathrm{M}$ Al-P plants. The number of fresh (unwilted) flowers in irrigated, $21 \mu \mathrm{M}$ Al-P plants was $\approx 29 \%$ greater than that of control plants $(P<0.01)$, which had significantly more fresh flowers than 5 $\mu \mathrm{M}$ Al-P plants $(48 \%$ more, $P<0.01)$.

\section{Discussion}

Marigold plants grown with reduced, alumina-buffered phosphorus availability had lower whole-shoot transpiration rates (Figs. 1 and 2) during conditions of low soil water potential. Since the plants had equal transpiration rates when expressed per leaf area regardless of phosphorus treatment, the reduced transpiration and slower desiccation in the buffered-phosphorus plants must have been a result of the reduced leaf area when less phosphorus was supplied. In addition, plants grown with $21 \mu \mathrm{M}$ Al-P had a lower $\mathrm{RWC}_{\text {pot }}$ at the wilting point than control or $5 \mu \mathrm{M}$ Al-P plants (Table 2), indicating more thorough use of the available water in the pot. This may be explained by the greater root length of the $21 \mu \mathrm{M} \mathrm{Al-P}$ plants (Table 2). The significant correlation between root length and $\mathrm{RWC}_{\text {pot }}$ (Fig. 4) lends support to the view that increased root length is associated with improved drought stress avoidance in $21 \mu \mathrm{M}$ Al-P plants. We previously showed that roots of marigold plants grown with conventional phosphorus fertilization (similar to control plants in this experiment) were distributed primarily near the irrigation drip tube, and not throughout the medium, while plants grown with lower P concentration supplied by Al-P had roots distributed throughout the medium and wilted more slowly dur-

Table 2. Leaf area, mean root diameter, estimated root length, and relative water content of the medium $\left(\mathrm{RWC}_{\mathrm{pot}}\right)$ at wilting from the experiment with root structure and water utilization on plants grown in SERAMIS with different Plevels. Values are means of 10 plants \pm SE. Different letters indicate significant difference on a $5 \%$ level ( $t$ test).

\begin{tabular}{lccccc}
\hline $\begin{array}{l}\text { P } \\
\text { availability }\end{array}$ & $\begin{array}{c}\text { Leaf area } \\
\left(\mathrm{cm}^{2}\right)\end{array}$ & $\begin{array}{c}\text { Total DW } \\
(\mathrm{g})\end{array}$ & $\begin{array}{c}\text { Root diam } \\
(\mathrm{mm})\end{array}$ & $\begin{array}{c}\text { Root length } \\
(\mathrm{m})\end{array}$ & $\begin{array}{c}\text { RWC }_{\text {pot }} \text { at } \\
\text { wilting }(\%)\end{array}$ \\
\hline control & $59.9 \pm 4.7 \mathrm{a}$ & $1.61 \pm 0.08 \mathrm{a}$ & $0.39 \pm 0.01 \mathrm{a}$ & $59.1 \pm 6.4 \mathrm{a}$ & $26.5 \pm 1.6 \mathrm{a}$ \\
$21 \mu \mathrm{M} \mathrm{Al}-\mathrm{P}$ & $47.3 \pm 3.2 \mathrm{~b}$ & $1.65 \pm 0.10 \mathrm{a}$ & $0.39 \pm 0.01 \mathrm{a}$ & $108.3 \pm 4.9 \mathrm{~b}$ & $21.0 \pm 0.8 \mathrm{~b}$ \\
$5 \mu \mathrm{M} \mathrm{Al}-\mathrm{P}$ & $26.9 \pm 3.0 \mathrm{c}$ & $0.90 \pm 0.58 \mathrm{~b}$ & $0.36 \pm 0.01 \mathrm{~b}$ & $65.1 \pm 8.0 \mathrm{a}$ & $27.1 \pm 2.2 \mathrm{a}$ \\
\hline
\end{tabular}

ing drought (Borch et al., 1998). In these experiments, subirrigation was observed to lead to deeper root proliferation, though this was not quantified. Plants grown with $5 \mu \mathrm{M}$ Al-P had root length similar to control plants, which probably explains why they, too, wilt at higher $\mathrm{RWC}_{\text {pot }}$ compared to $21 \mu \mathrm{M}$ Al-P plants. Plants grown with $5 \mu \mathrm{M}$ Al-P had poor overall growth, shown by lower shoot dry weight (Table 1), reduced root length (Table 2), and less root branching (Fig. 3) compared with $21 \mu \mathrm{M}$ Al-P plants. These smaller plants would be expected to have less water usage (Figs. 1 and 2), which probably accounted for the fact that they wilted last.

We previously reported that bean (Phaseolus vulgaris) roots grown in sand culture had lower lateral root density under deficient (1.1 $\mu \mathrm{M})$ than sufficient $(8.6 \mu \mathrm{M}) \mathrm{P}$ availability (Borch et al. 1999). Chrysanthemum roots grown in nutrient solution also showed higher lateral root density under sufficient $(100 \mu \mathrm{M})$ than deficient $(1 \mu \mathrm{M}) \mathrm{P}$ availability (Hansen and Lynch, 1998). In this study, marigold roots grown in SERAMIS had equal lateral root density when grown with 5 or $21 \mu \mathrm{M}$ Al-P, and higher lateral root density under very high $\mathrm{P}$ availability (controls) (Fig. 3). Thus, $\mathrm{P}$ can regulate root distribution through its effects on root elongation and spacing of lateral roots. This study shows that the high P concentrations supplied to control plants actually suppresses overall root growth in marigold, indicating that this typical fertilization regime supplies excessive $P$ nutrition. The fact that total root length is decreased by $45 \%$ (Table 2) while lateral root density is increased by $\approx 40 \%$ (Fig. 3) compared with $21 \mu \mathrm{M}$ Al-P plants suggests that main root elongation, rather than lateral root initiation and growth, is reduced by excess P. This would result in restricted root distribution within large volume containers.

The reduction in leaf area in $21 \mu \mathrm{M} \mathrm{Al-}$ $P$ plants compared with control plants was at least partially compensated by increased net photosynthesis per unit leaf area when photosynthesis was measured on a whole plant basis. The most important factor responsible for increased net photosynthesis per unit leaf area is probably the reduction of internal canopy shading resulting from the smaller leaf area of $21 \mu \mathrm{M} \mathrm{Al-P}$ plants, though the increase in chlorophyll content often found in plants grown under lower phosphorus (Hecht-Buchholz, 1976; Rao and Terry, 1989) could play a role as well. These photosynthesis measurements were taken in a growth chamber under relatively low irradiance $\left(73 \pm 18 \mu \mathrm{mol} \cdot \mathrm{m}^{-2} \cdot \mathrm{s}^{-1}\right)$, more characteristic of the post-production (shipping and retail) environment than of production conditions. Plants grown with $21 \mu \mathrm{M} \mathrm{Al-P}$ in this experiment had $\approx 33 \%$ more flowers than control plants, similar to the difference in the long-term drought experiment $(28 \%)$ and to that previously reported for plants evaluated in the greenhouse (Borch et al., 1998). The reduced intraplant shading may therefore explain the lack of impact of reduced leaf area on flower number and total plant DW. 


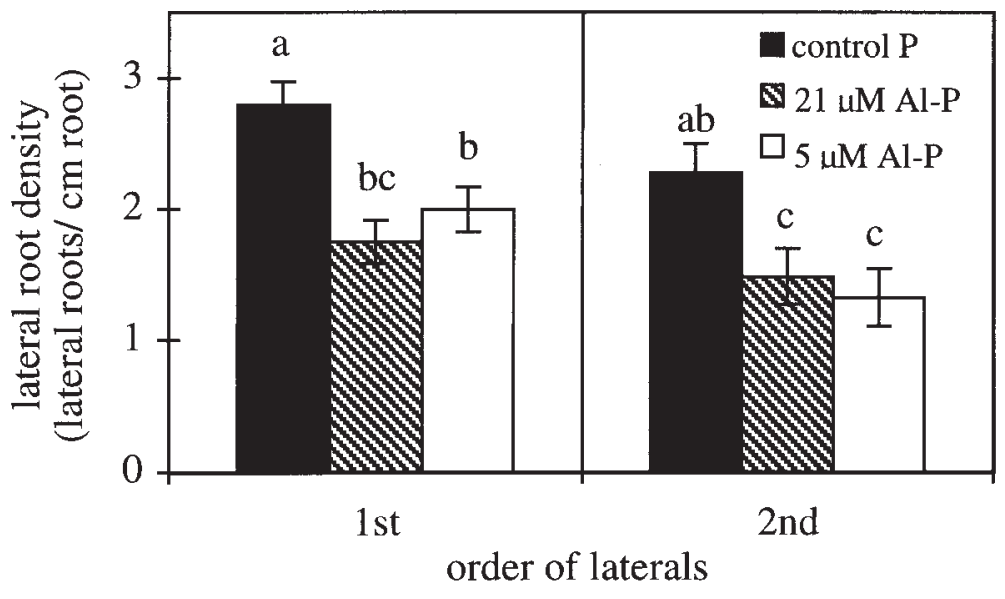

Fig. 3. Density of first and second order lateral roots (as number of lateral roots per cm originating root) on marigold roots grown with 3 different $P$ treatments. ANOVA: first order laterals, $\mathrm{F}=9.99, P<0.01$; second order laterals, $\mathrm{F}=5.37, P<0.01$. Values are means of 10 plants $+\mathrm{SE}$.

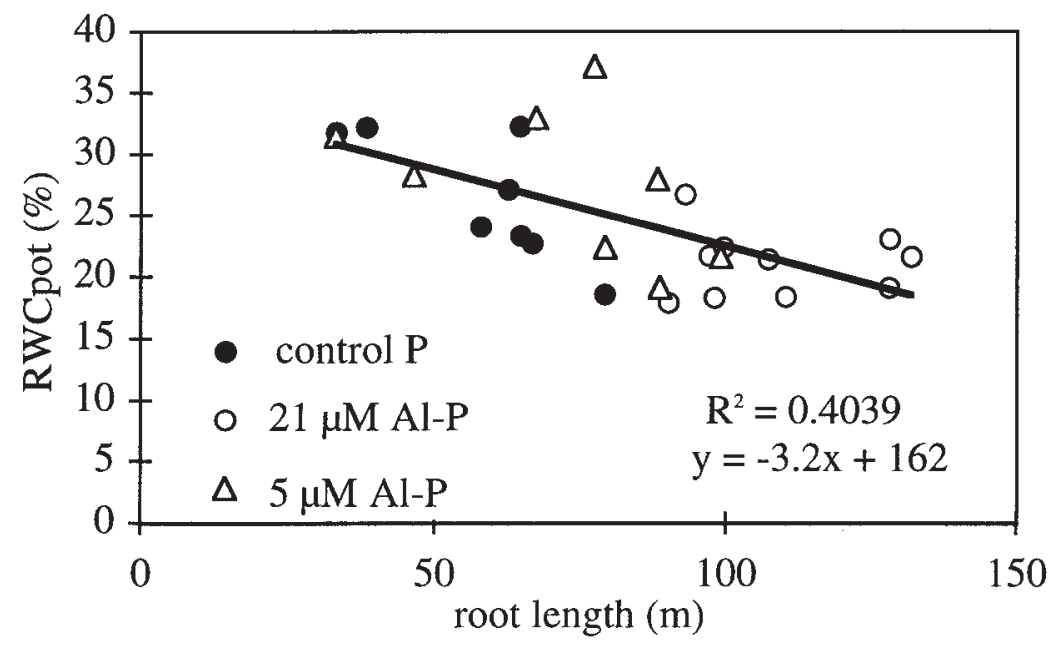

Fig. 4. Relationship between root length and relative water content of the medium at wilting $\left(\mathrm{RWC}_{\mathrm{pot}}\right)$ of control P, $21 \mu \mathrm{M}$ Al-P and $5 \mu \mathrm{M}$ Al-P plants at wilting. Each point represents the $\mathrm{RWC}_{\text {pot }}$ of one plant. The line was fit to data from all three phosphorus treatments by linear regression. $r^{2}=0.40, P<0.05$

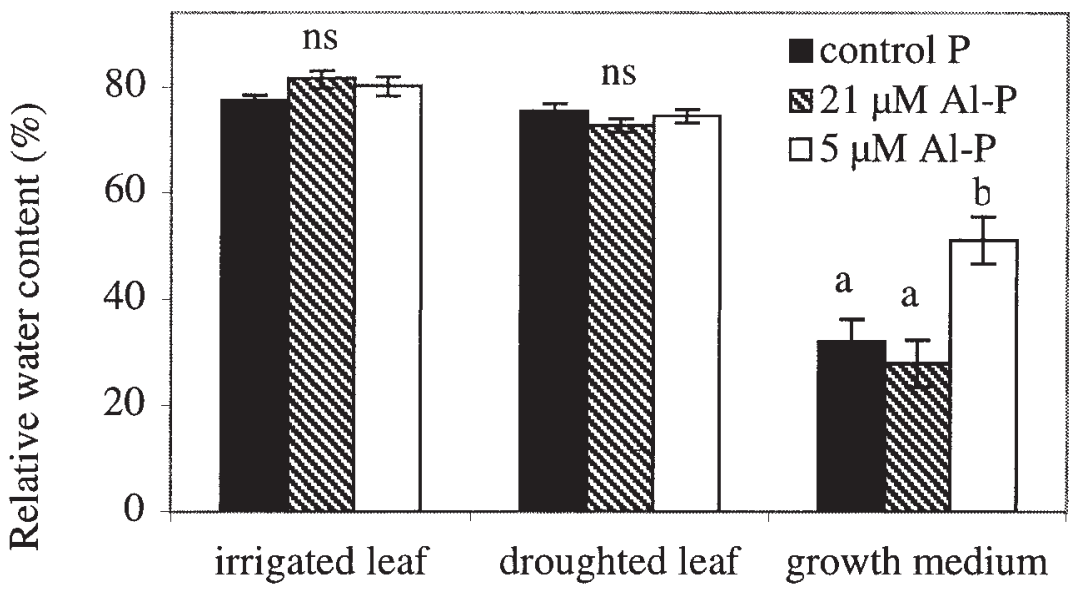

Fig. 5. Relative water content (RWC) of leaves and growth medium after three weeks of water stress for plants grown with control P, $21 \mu \mathrm{M} \mathrm{Al-P}$ and $5 \mu \mathrm{M}$ Al-P. Pots started at 100\% RWC of the medium. Values are shown for irrigated as well as stressed leaves. Values are means of 10 plants \pm SE.
Short-term drought did not specifically reduce photosynthetic rates. The greater drought resistance of $21 \mu \mathrm{MAl}$-P plants compared with controls is therefore not due to a differential inhibition of photosynthesis.

All plants exposed to long-term drought (by irrigating with half their previous rate of water use for 3 weeks) showed signs of water stress (lower leaf yellowing and abscission). Drought had a more negative effect on $5 \mu \mathrm{M}$ Al-P plants than on the other plants, as evidenced by lower dry weight (data not shown). However, these plants failed to fully exploit the available water, since the $\mathrm{RWC}_{\mathrm{pot}}$ was considerably higher after 3 weeks of drought for $5 \mu \mathrm{M}$ Al-P plants than for $21 \mu \mathrm{M}$ Al-P or control plants (Fig. 5). The reduced root growth in $5 \mu \mathrm{m}$ Al-P plants observed in the previous experiment (Table 2) may have been exacerbated by the drought, resulting in even greater stunting of root growth and consequent failure to explore the medium. Previous work with sorghum and bean has shown that phosphorus-deficient plants had shorter roots and poor drought resistance compared to phosphorus-sufficient control plants (Al-Karaki et al., 1996). In this experiment, there were no significant differences between control and $21 \mu \mathrm{M} \mathrm{Al-P}$ plants in plant dry weight, flower wilting, or relative water content of leaves or medium after 3 weeks of drought stress.

In summary, decreased but steady phosphorus availability, achieved by amending soilless medium with a solid-phase phosphorus-buffer, improved drought tolerance chiefly through avoidance mechanisms. Several factors probably contributed to this. Smaller leaves transpired more slowly. Low, but sufficient, phosphorus availability resulted in longer roots with lower lateral root density, which increased root distribution within the container and improved water acquisition and drought avoidance.

\section{Literature Cited}

Al-Karaki, G.N., R.B. Clark, and C.Y. Sullivan. 1996. Phosphorus nutrition and water stress effects on proline accumulation in sorghum and bean. J. Plant Physiol. 148:745-751.

Anuradha, M. and A. Narayanan. 1991. Promotion of root elongation by phosphorus deficiency. Plant Soil 136:273-275.

Armitage, A.M. 1993. Bedding plants. Prolonging shelf performance. Ball Publishing, Batavia, IIl.

Borch, K., K.M. Brown, and J.P. Lynch. 1998. Improvement of plant stress resistance with low phosphorus. HortTechnology 8:575-579.

Borch, K., T.J. Bouma, K.M. Brown, and J.P. Lynch. 1999. Ethylene: A regulator of root architectural responses to soil phosphorus availability. Plant Cell Environ. 22:425-431.

Elliott, G.C. 1992. Imbibition of water by rockwoolpeat container media amended with hydrophilic gel or wetting agent. J. Amer. Soc. Hort. Sci. 117:757-761.

Elliott, G.C., J. Lynch, A. Läuchli, and E.L. Anderson. 1983. Solid-phase buffering of phosphate in sand cultures. J. Plant Nutr. 10:1499.

Hansen, C.W. and J. Lynch. 1998. Response to 


\section{Soil Management, Fertilization, \& Irrigation}

phosphorus availability during vegetative and reproductive growth of chrysanthemum: II. Biomass and phosphorus dynamics. J. Amer. Soc. Hort. Sci. 123:223-229.

Hecht-Buchholtz, C. 1967. Über die Dunkelfärbung des Blattgrüns bei Phosphormangel. Z. Pflantzenernäehr. Bodenk. 118:12-22.

Hsiao, T.C. 1990. Measurements of plant water status, p. 243-279. In: B.A. Steward and D.R. Nielsen (eds.). Irrigation of agricultural crops. Agron. Monogr. No. 30, Amer. Soc. Agron., Madison, Wis.

Lin, Y-1. P., E.J. Holcomb, and J. Lynch. 1996.
Marigold growth and phosphorus leaching in a soilless medium amended with phosphoruscharged alumina. HortScience 31:94-98.

Lynch, J., A. Lauchli, and E. Epstein. 1991. Vegetative growth of the common bean in response to phosphorus nutrition. Crop Sci. 31:380-387.

Lynch, J. and S.E. Beebe. 1995. Adaptations of beans (Phaseolus vulgaris L.) to low phosphorus availability. HortScience 30:1165-1171.

Murphy, J. and J.P. Riley. 1962. A modified single solution reagent for the determination of phosphate in natural waters. Anal. Chim. Acta 27: 3136.
Rao, I.M. and N. Terry. 1989. Leaf phosphate status, photosynthesis, and carbon partitioning in sugar beet. I. Changes in growth, gas exchange, and Calvin cycle enzymes. Plant Physiol. 90: 814-819.

Reisenauer, H.M. 1964. Mineral nutrients in soil solution, p. 507-508. In: P.L. Altman and D.S. Dittmer (eds.). Environmental biology. Fed. Amer. Soc. Expt. Biol., Bethesda, Md.

Starkey, K.R. and A.R. Pedersen. 1997. Increased levels of calcium in the nutrient solution improves the postharvest life of pot roses. J. Amer. Soc. Hort. Sci. 122:863-868. 